\title{
Clearance of explosive ordnance: the answer to all evils?
}

\author{
F. Jaenig \\ German Scientific-Technical Association for Environmental Remediation \\ and Brownfield Redevelopment, Germany
}

\begin{abstract}
Wars do bring harm and death and, even after the end of war, legacies create continuing danger to human beings. Thus, in former operational zones, every 22 minutes a human being is injured or killed by unexploded ammunition. As a first activity a clearance of explosive ordnance is carried out, in order to eliminate the danger of contact. Depending on expected depth and type of ammunition, various methods of detection and clearance are applied, all of which have in common the detection of metals, because of suiting, such as boxes for energetic materials (EMs). After that, the clearance of the explosive ordnances detected such as shells, bombs, ammunitions - is stipulated, whereupon a serious intervention in the soil in both area and depth can take place. As an inevitable consequence of this, EMs that have leaked from bins or EMs that are in broken bins remain in the soil. In addition, the soil's primarily punctual contamination with EMs could be dispersed across the complete area of clearance. In the soil the particles of the EM are exposed to elution, thus groundwater-contamination with EM is affected due to the type and duration of exposition. Because of the toxic and carcinogenic properties of these substances, such groundwater- and soil-contaminations can cause hazard to sensitive goods. The anonymous German practical example presented shows that high and persistent concentrations of EMs in the leachate were detected after an extremely cost-intensive clearance of explosive ordnance, resulting from a temporary mobilization of EM-particles within the scope of clearance and from EM-soil contaminations not cleared. Thus, a conjunction of clearance of explosive ordnance and soil remedial actions is mandatory, in order to ensure satisfying results of a remediation or clearance.
\end{abstract}

Keywords: clearance of explosive ordnance, geophysical detection, remediation. 


\section{Introduction}

In former operational zones human beings are injured or killed periodically by unexploded ordnance devices (UXOs) or left behind ammunition. Even in Germany explosive ordnances deriving from World Wars I and II and military use of areas are found despite an intensive clearance of explosive ordnance for decades.

The imminent danger for human beings is not as high as in accordant conflict areas discussed in the media though. In Germany many areas are identified, which have the suspicion of existence of explosive ordnances, so that it is possible to take correspondent measures in the run-up to any activities in the area. However, unexpected UXOs or ammunition are encountered, mainly during infrastructural works.

In Germany the clearance of explosive ordnance consists of investigation, sounding, excavation, transport and finally demolition of the explosive ordnances. The demolition (e.g. by detonation) is mostly carried out governmentally. The other activities can also be carried out by private specialty firms with accordant individual-related authorizations.

Corresponding to German federal state law "explosive ordnances" are defined as "bombs and ammunition and their components, which contain energetic materials (EM)" [1]. The nomenclature "explosive ordnance" refers to the bin of the EM being enclosed in it, like TNT, but not to the EMs themselves. Hence, for instance a bulk TNT-lump is not classified as explosive ordnance and will not be incorporated in the clearance of explosive ordnance. For this reason, after the clearance of explosive ordnance has taken place the imminent danger for human beings is eliminated, but often these cleared areas still present a danger for soil and groundwater: EM-lumps remaining in the area are dissolved by precipitation and elute into the topsoil, where they can be adsorbed reversibly, resulting in a soil contamination. By permanent ad- and desorption, caused by environmental changes in the soil followed by rainfalls and changes in the soil, the EMs dissolved in the leachate finally reach the groundwater.

\section{Clearance of explosive ordnance}

The clearance of explosive ordnance follows a methodical procedure consisting of four phases [1], see Table 1 .

In the framework of the historical investigation on the basis of archival materials, the potential explosive ordnance load is reproduced regionally and genetically in order to evaluate the potential impact [1].

If the suspicion of an explosive ordnance load is confirmed by the historical investigation, a technical investigation follows with the objective of a risk assessment. This comprises the representation of type, position and amount of explosive ordnances assumed/confirmed, their actual situation, their facility for detonation and thus, their potential effect on subjects of protection. In the framework of the technical investigation test areas are planned, which shall represent the distribution of explosive ordnances on the site. These test areas are 
Table 1: Four phases of the methodical proceeding of the clearance of explosive ordnance.

\begin{tabular}{|c|c|}
\hline Phase & Historical Investigation \\
\hline 1 & Technical Investigation including risk assessment \\
\hline 2 & Clearance concept including tendering and awarding \\
\hline 3 & Clearance \\
\hline 4 & \\
\hline
\end{tabular}

investigated geophysically and cleared subsequently, so that an assessment for the whole site can be made on that basis [1].

If a clearance of explosive ordnance is inevitable, a clearance concept is developed, which presents different models of clearance methods for a defined objective. Objectives can be the clearance of explosive ordnances without restriction of any kind (clearance of the whole area under the terms of state of the art), the restricted clearance of explosive ordnance (clearance is limited to depth/area/type) or simply safety measures [1]. The tendering and awarding is carried out on the basis of the clearance concept after that.

Finally, the clearance of explosive ordnance is carried out. This consists of sounding and localizing of the explosive ordnances, their excavation and recovery and their transport for demolition (or their detonation in situ if necessary if safe transport cannot be ensured).

The clearance discerns five methods, depending on the problem, which can also be applied combined [1]: 1. Visual clearance: Here, visible explosive ordnances shallow tipped or protruding from soil are removed from the area. 2 . Clearance during the construction phase: Here, during excavation in layers, the horizontal and vertical faces of the pit are sounded and located explosive ordnances are removed. 3. Clearance of UXOs/punctual soil influenced clearance: UXOs are excavated and removed after sounding via special excavation techniques. 4. Holohedral, punctual soil influence clearance: The whole area is sounded, and localized explosive ordnances are removed after excavation. 5. Clearance after excavation of soil and other materials ("volume clearance"/separation): Mutually, the soil is sounded and removed in layers. Major explosive ordnances are recovered during removal. The excavated soil is stored temporarily on cleared areas and is checked visually by sensor. Alternatively, the excavated soil is treated in screening plants, magnetic separators or whirler-type separators.

Because "explosive ordnance" signifies bins containing EMs, the sounding and locating provides for searching for metals, which serves for bins. The relevant bins can be magnetic (mostly ferrous) or antimagnetic (e.g. brazen bins). The detection can be carried out laminarily and in the borehole. Methods of detection are geomagnetics, electromagnetic-2-inductor-systems and radar [2]. 


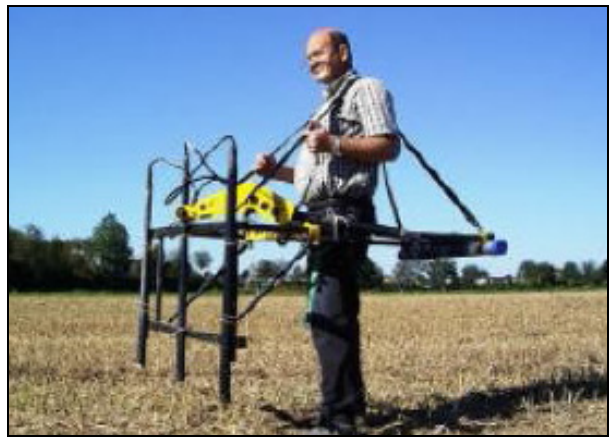

Figure 1: Geomagnetic detection.

Table 2: $\quad$ Different ranges depending on the bore diameter.

\begin{tabular}{|c|c|c|c|c|c|c|c|}
\hline bore diameter $[\mathrm{cm}]$ & 2 & 6 & 10 & 16 & 20 & 30 & 34 \\
\hline range $[\mathrm{m}]$ & 0.6 & 1.5 & 2.1 & 2.75 & 3.1 & 3.7 & 4.0 \\
\hline
\end{tabular}

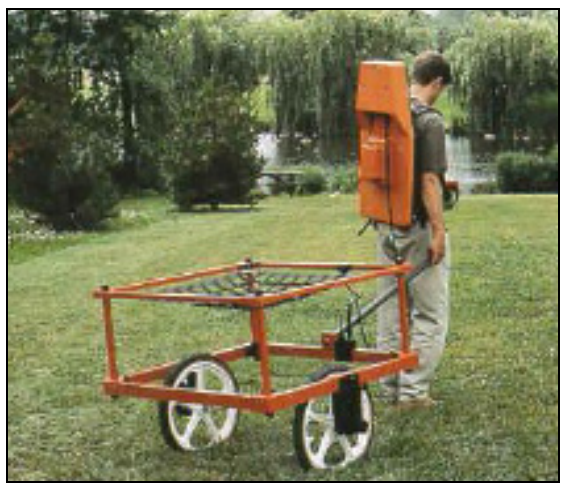

Figure 2: Detection with an electromagnetic-2-inductor-system.

Geomagnetics utilize the earth's natural magnetic field, which is overlain by local magnetic fields of ferromagnetic compounds in the subsoil, see figure 1. By detecting the variation of the magnetic field, or of the gradient, the compound is located. Depending on the dimension of the compound the location is made in different depths, see table 2. Magnetometers only detect magnetic compounds. In addition, this method is not useful in areas containing magnetic compounds, such as cables, rails, cars etc., because the small subsurface fields of the explosive ordnances are overlain by the influence of the major components [2].

The electromagnetic-2-inductor-system induces a primary magnetic field by an emitting inductor, which excites a secondary magnetic field in the conductive subsoil by induction, recorded with a receiving inductor, see figure 2 . With this method the conductivity of the subsoil is examined, so that antimagnetic 
compounds can also be detected. However, the method is susceptible to metallic compounds, such as cables or metallic objects on the surface, whose signals can overlay the ones of the explosive ordnances [2].

Radar emits electromagnetic waves into the subsoil by a transmitting aerial, see figure 3 . These waves are leaked and reflected by compounds or geologic layers, resulting in changes of the conductivity. A receiving aerial records these waves, so that changes of the conductivity in the subsoil can be detected. The range of the waves depends highly on the geology: sandy subsoil is applicable; clayey soil is barely applicable, because the range is strongly reduced. In additionally, humidity has an effect on range. In dry, sandy soils ranges of ca. $5.0 \mathrm{~m}$ are obtained. The significant advantage of radar is the applicability within splitting distance to cables, rails or other compounds. However, radar also localizes cavities, groundwater or geological compounds, so that the cause of an anomaly cannot be determined definitely [2].

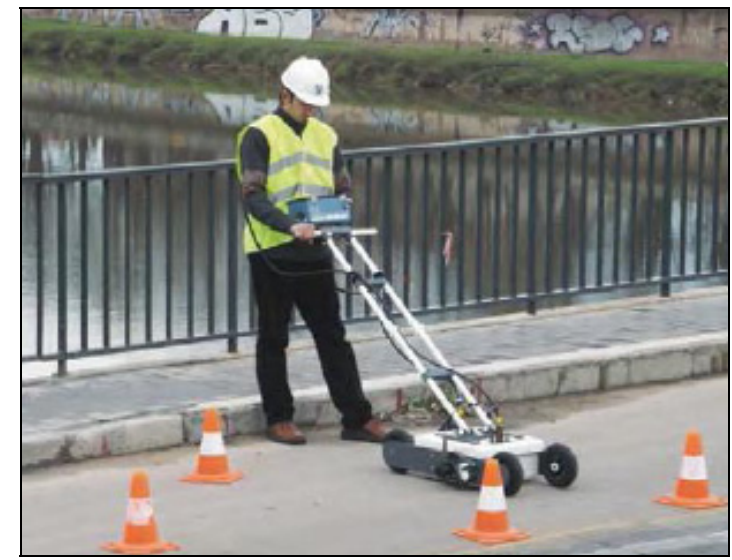

Figure 3: Detection with radar.

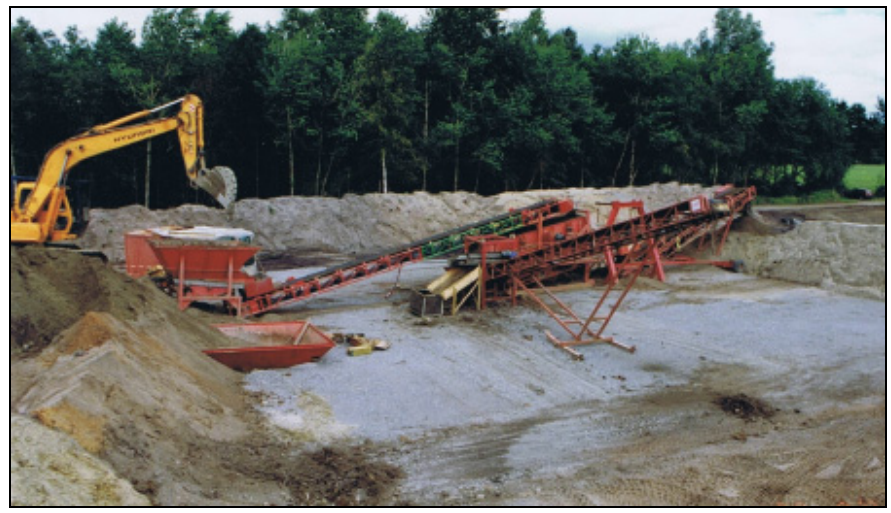

Figure 4: $\quad$ Screening plant in situ. 
After locating, the excavation takes place, which is usually carried out by an excavator. The subsoil is excavated and stocked in piles. From the piles the explosive ordnances are separated manually or mechanically. By manual separation the single explosive ordnances are localized by geophysical methods and then picked out. By mechanical separation the excavated soil is sieved. In doing so, the mesh size is attuned to the smallest explosive ordnance estimated. In addition, the separation can be carried out with screening plants (see figure 4) that have different methods of separation (sieve, magnetic separator, whirler-type separator). The soil cleared from the explosive ordnance is backfilled again in situ.

\section{Soil and groundwater contamination}

The clearance of explosive ordnances can result in harmful impacts to the environment, due to the significant changes in the soil: The environment is highly affected by the use of forest clearance, the destruction of the plant canopies and the soil layers and the adherent loosening of the soil [1]. In addition, a hazard to soil and groundwater can be highly enhanced by the clearance of explosive ordnances: On the one hand, explosive ordnances can be highly corroded, because of long-lasting exposure time, so that the metallic bins burst with moderate mechanical strain, resulting in a discharge of the EM contained, see figure 5. In particular, the application of separation equipment causes soil contamination. On the other hand, exposed remnants of EMs (e.g. TNT, RDX) are existent, particularly in areas where explosive ordnances were launched or blasted (e.g. former artillery ranges, demolition areas constructed after the World Wars).

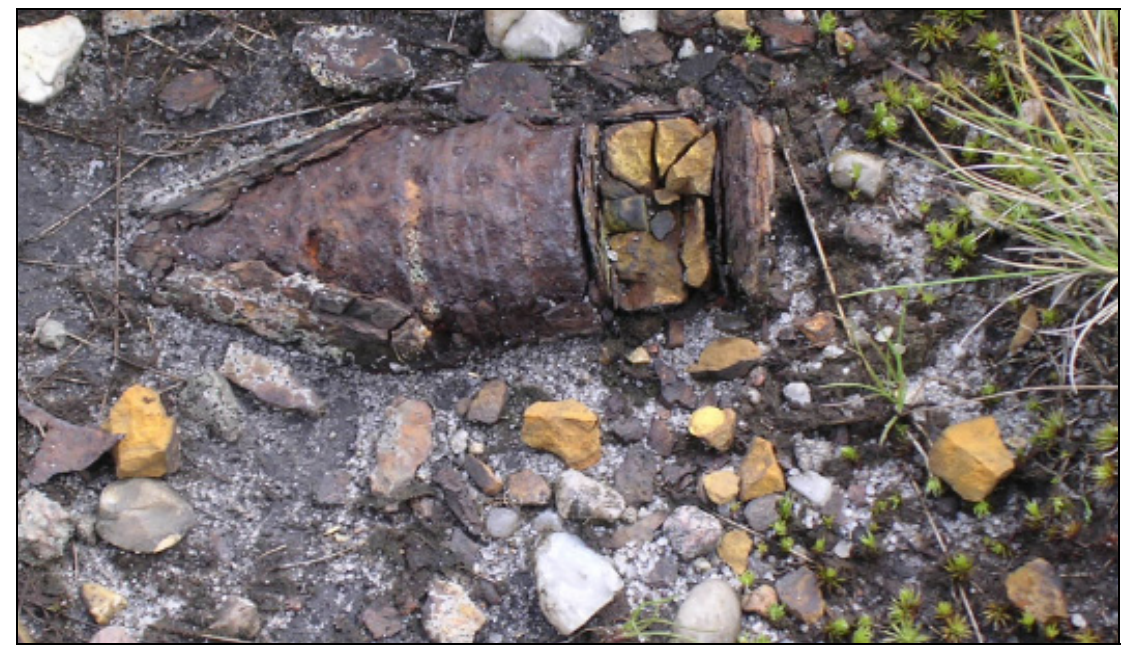

Figure 5: Corroded bin with scattered EMs. 
Due to the soil changes during clearance, the EM-rests will be displaced deeply and extensively, because they are not included in the separation. Thus, the EMs remain in the soil and will be refilled after clearance in combination with the "cleaned" soil, i.e. the sieved piles.

In consequence of the high loosening of the soil, the extensive dispersion of the EMs and the potential crushing by the mechanical strain, the mobilization of the EMs is promoted: Leachate can penetrate the soil more easily and dissolve finely dispersed EMs. Thus, EMs such as TNT and RDX - after the filling of the ordnance - can infiltrate into the groundwater by elution. Due to their carcinogenicity and toxicity, various EMs and their metabolites represent a relevant hazard to sensitive goods, not only the microflora and fauna in the soil and the aquifer, but also for human beings in the case of untreated water being consumed.

In Germany various former ammunition production facilities and former demolition areas (e.g. artillery ranges) show groundwater contamination plumes downstream, which result from not only remaining EM-Hot-Spots, but also from former mine craters, which are cleared of explosive ordnances but not cleared of EMs.

\section{Anonymous practical example}

In World War I an ammunition production facility for "the manufacture of high explosives for projectiles' and ammunitions' filling" was constructed in Germany. The facility consisted of a pressing plant for compacts made of picric acid, a filler point of artillery shells and a plant for delaboration.

The production and manufacture was limited to the wartime of World War I; during this time several thousand tons of TNT and DNB subsidiary were produced, several million compacts of picric acid were pressed and several million shells/demolition charges made of casted charges of TNT, DNB ammonium-/sodium-nitrate and their mixtures were filled. The plant for delaboration temporarily had the capacity of several thousand units per day, and after the end of the war an interim storage of several thousand shells was documented.

After the war a spate of explosions happened during delaboration, resulting in a nearly complete demolition of the facility and an extensive dispersion of ammunition in the circumference. Because of the lack of environmental awareness at that time, both small-area contaminations by production/delaboration and extensive contamination by the explosion accidents of the soil with miscellaneous EMs occurred. The aftermath debris of the explosions and the ammunition dispersed were collected and the remained inventory of ammunition was demolished by detonation or burning out. The activities were discontinued in 1929 and the area of the ammunition plant was declared "cleared of explosive ordnance".

During clearance of the explosive ordnance huge masses of soil were excavated and cleared by screening plants that have mesh openings of some centimetres and backfilled after clearance. Thus, the cleared area was free of 
explosive ordnances but not free of EMs: EM-lumps with diameters of several centimetres remained in the soil. In addition, major lumps were shred mechanically by sieving and heterogeneously dispersed in the whole excavation/sievings. EMs eventually enclosed in damaged bins got into the soil due to the break-up of the bins while sieving. The remaining EMs reached the ground- and surfacewater by erosion and elution. Due to an average annual rainfall of $1,200 \mathrm{~mm}$ and a presumed infiltration of $10 \%$, the ground- and surfacewater has per $\mathrm{m}^{2}$ an input of $120 \mathrm{l}$ p.a. of EM-contaminated water, which means $36,000 \mathrm{~m}^{3}$ p.a. for the whole area of ca. $300,000 \mathrm{~m}^{2}$.

Thereby the EM-input depends on the particle size of the EM particles and on the substrate: major EM-lumps have per se a smaller surface for elution than smaller lumps. That is why they remain longer, particularly in the soil, than small lumps or powdery dispersed EMs. However, major EM-lumps are a longlasting source of emission if they remain in the soil. Depending on the dimension of the contaminated area and the amount of the existent EMs in it, significant ground- and surfacewater contaminations can be generated.

The transport and the spreading of the dissolved EMs in the saturated and unsaturated zone depends on the characteristics of the EMs and the soil: EMs are able to adsorb temporarily on clay minerals, organic substances and ferric (hydr)oxides present in the soil, so that their transport can be retarded by reversible adsorption.

Thus, a decreasing of the spreading velocity is indicated when the amount of adsorbents in the soil increases. In the process, the adsorption of EMs is co-determined by the concentration equilibrium, which exists between the dissolved phase (concentration of the pore water) and the adsorbed phase (concentration of the adsorbent/the soil). Thus, the real spreading velocity in situ is overlain by the changing of sorption and release processes resulting from changes in the solution phase concentration of the EMs caused, e.g., by the discontinuity of the source. Therefore, changes in the soil resulting from the clearance of explosive ordnance produce an alteration of the source of contamination, which influences the concentration equilibrium seriously. Hence, after changes, increased mobilization of EMs arises, which becomes manifest in more or less long-lasting increased ground- and surfacewater concentrations of EMs, until a new concentration equilibrium is recalibrated, adapted to the new conditions.

In the case of the practical example presented, a mobilization of EMs also occurred because of a temporary leakage of red water coloured by EMs.

However, the described leakage of EMs was taken into account initially in a soil remediation and soil protection measurement carried out up to now. In the framework of the physical safeguarding of the site, an infiltration ditch was passed around the core area of the former facility, with which contaminated leachate is collected and fed into an activated carbon filter. Concerning the emission of the EMs in the deep subsurface, initially only monitoring was carried out, because the bedrock is relatively low-permeable and the transport of groundwater happens via fissures. Here, at the identified emersion points, the water is chemically analyzed regularly. 
Despite eliminating the imminent danger for human beings by explosive ordnances, the former ammunition production facility still represents a danger for human beings and the environment, because the soil in the area of the former facility will be a source of emission for hundreds of years, caused by finely dispersed EMs resulting from the production, delaboration, accidental explosions and clearance of explosive ordnances.

\section{Conclusions and perspectives}

The practical example shows that the site was cleared with extraordinary expense, but the clearance of explosive ordnance resulted in an extensive, heterogenic, fine dispersion of the accordant EMs. Because easily accessible contamination-Hot-Spots were not eliminated and EM-contaminated soil was backfilled, high EM-concentrations of the leachate are expected for an indefinite period.

To protect both the environment and human beings and in order to save expenses in the same way, a conjunction of the clearance of explosive ordnance and soil remedial actions is reasonable in the run-up to any activities. With a conjunction of both procedures it can be ensured that both soil free of explosive ordnance and of EMs is backfilled, Hot-Spots of EMs (and other contaminants) are excavated separately, so that the contaminants in the framework of the clearance of explosive ordnances will not be dispersed extensively or remain in the soil and temporary mobilizations of EMs by changes in the soil are considered in the run-up and their inhibition will be assured by appropriate attended techniques.

Because the progression of the methodical procedure of a soil remediation is similar to that of a clearance of explosive ordnance (see tables 1 and 3), a conjunction means no extravagant additional expenditure per se. Data-recall facilities, appropriate investigations and interpretations can be carried out hand in hand. In addition, the clearance and remedial activities can be technically carried out at the same time.

Thus, it is not for technical reasons but on legal grounds by the mentioned definition of "explosive ordnance", that the clearance of explosive ordnances solely eliminates explosive ordnances and does not clean the area of EMs as well. In addition, one has to deal with the competences of diverse authorities for

Table 3: $\quad$ Four phases of the methodical proceedings of a soil remediation.

\begin{tabular}{|c|c|}
\hline Phase & Historical Investigation \\
\hline 1 & Technical Investigation including risk assessment \\
\hline 2 & Concept of remediation (including tendering and awarding) \\
\hline 3 & Remediation \\
\hline 4 & \\
\hline
\end{tabular}


the clearance of explosive ordnances and the enforcement of the "German Federal Protection Act and Ordinance" (BBodSchG), an environmental law to be applied in Germany for the investigation, assessment and remediation of soil contaminations.

Thus, the aim is that, via associations, occupational unions, professional organisations and similar institutions, which are engaged in both problems, attention is paid to formulating appropriate articles for the developing policy, suitable settlements in the form of guidelines and to ensuring future adoption into standardized guidelines, rules and regulations.

\section{Acknowledgements}

I thank the German Scientific-Technical Association for Environmental remediation and Brownfield Redevelopment, namely Mrs. Sabine Gier, for permission for publication and my colleagues Mr. Uwe Kaufmann and Mr. Tobias Bausinger, $\mathrm{PhD}$, for the critical review of the manuscript.

Thanks as well go to my colleagues Mr. Alexander Schwendner and Mr. Jürgen Klatt for providing photos.

Furthermore I thank the Tauber company, namely Mr. Norbert Schmidt and Mr. Simon Gremmler for providing photos and for the elaboration of the geophysical investigation methods.

\section{References}

[1] Arbeitshilfen Kampfmittelräumung - Arbeitshilfen zur wirtschaftlichen Erkundung, Planung und Räumung von Kampfmitteln auf Liegenschaften des Bundes $(A H K M R)$, Bundesministerium für Verkehr, Bau und Stadtentwicklung \& Bundesministerium der Verteidigung, Berlin, 2007.

[2] Gremmler, S., Erkundungstechniken in der Kampfmittelsuche, Tauber DeDeComp GmbH, Hannover, 2009. 